\title{
Writing for Nonprofits in a Professionally-Oriented Institution: Using Rhetorical Genre Studies to Teach Flexibility
}

\author{
Kathryn J. Gindlesparger * \\ January 4, $2019^{\dagger}$
}

\begin{abstract}
Teaching rhetorical flexibility within a nonprofit environment to professionally-oriented students can be challenging because the seemingly transactional genres of nonprofit communication, such as grant applications, do not appear to invite improvisation. This genre analysis assignment from a Writing for Nonprofits course asks students to reflect on the intersections of their own values as emerging communications professionals and the rhetorical choices they made while writing in a nonprofit genre of their choice. To complete the assignment described here, students created a "personal code" that describes their professional values and used the code to write a genre analysis that examines the rhetorical choices made in a nonprofit genre. This "reflective genre analysis" allows students to recognize their own agency in the negotiation of genre and reinforces the idea that professional behavior is rhetorical and situational.
\end{abstract}

\section{Introduction}

Communications work in the nonprofit sector can feel transactional, as requests for funding and reports are often submitted using standardized forms, and genres associated with funding applications often emphasize grammatical and mechanical appropriateness rather than substance (Barrett, 2013). One challenge of teaching Writing for Nonprofits, a 300-level elective in my institution's Communications Program, was teaching the rhetorical flexibility necessary to navigate these seemingly simple genres while also

\footnotetext{
${ }^{*}$ Communication Program, Thomas Jefferson University, Kathryn.Gindlesparger@jefferson.edu. Copyright 2019 Kathryn J. Gindlesparger. This work is licensed under a Creative Commons AttributionNonCommercial 4.0 International License (http://creativecommons.org/licenses/by-nc/4.0/).

${ }^{\dagger}$ Submitted, 2/9/2018; Accepted, 10/28/2018.
} 
maintaining the goals of the community partners my students chose to research. Key in striking this balance was using reflection as a tool for encouraging students to understand their context as emerging communications professionals.

Teaching rhetorical flexibility is especially important within my own institutional context, a professionally-oriented university with a focus on the liberal arts where only $1 \%$ of students in the most recent institutional headcount list their major as undeclared, and $75 \%$ of students report that they are "quite" or "very" interested in "acquiring job or work-related knowledge and skills" (NSSE, 2012). By "rhetorical flexibility" I mean the audience awareness necessary to anticipate which rhetorical appeals are expected, but also those which might be appropriate but not necessarily expected. While transactional communication is certainly valued within the nonprofit sector because it secures funding by way of grants, market pressures on nonprofits are also changing the way organizations find and secure money. According to a 2014 review of the nonprofit sector, only $9.2 \%$ of reporting public charities' revenue came from government grants, whereas $73.1 \%$ came from fees and $12.9 \%$ came from private contributions (McKeever \& Pettijohn, 2014). These percentages are recommended to nonprofits by the Foundation Center (n.d.), demonstrating the importance of rhetorical skill in donor cultivation and fee structure creation, two areas of financial development in which the associated genres are fluid and emerging. This shift in funding priorities demonstrates the importance for nonprofit professionals to be able to identify opportunity and anticipate appropriate rhetorical appeals.

While improvisation and flexibility of performance are critical to communication within nonprofits, disciplinary boundaries within professional education can discourage the risk-taking necessary to learn these rhetorical skills. In fact, disciplinary pedagogical practices can encourage pre-professional students to see the professional identities of those in the field as static, unchanging, and a blanket persona to be adopted, rather than a fluid performance of values (Brady \& Schreiber, 2013). As a corrective to this phenomenon, I wanted to teach my students to be able to recognize how their own personal and emerging professional values are performative and can be presented strategically. I framed the course using Rhetorical Genre Studies (RGS) and asked students to reflect in their final genre analysis on their own emerging professional values as a way to enhance metacognition of the relationships between the (sub)disciplinary expectations of nonprofit communications and students' own subjectivity. Metacognitive practices like reflection allow writers to "recall, reframe, and relocate knowledge and practices" (Taczak, 2015, p. 79). Reflection about genre use, specifically, can provide students insight into disciplinary values, as has been discussed in this journal (Grouling, 2018). In the case of this assignment, the emphasis on rhetorical flexibility pushes students to consider how the fluid genres of program and financial development will require them to strategically position their own values within the constraints of those unstable genres.

The assignment described here, a "reflective genre analysis," encompasses two rhetorical moves: an analysis of a nonprofit genre written during the semester and a reflection on how the genre was performed. Leading up to the assignment, students examined 
various genres common in nonprofit settings, including annual reports, donation receipts, thank-you letters, and email newsletters and wrote their own program proposals and funding proposals. In the reflection portion of the assignment described here, students analyze how their own emerging professional values intersect with one of the genres they examined during the semester. In this first cohort of students, all students chose to examine an application for funding.

\section{Description of Assignment: Balancing Reflection and Genre Awareness}

To give students real-world experience in the flexibility of nonprofit genres, a best practice in composition and in technical and professional communication has been for faculty to pursue service-learning collaborations with local organizations (Allen \& Benninghoff, 2004). In designing communications for local organizations, students learn about what genres are typical and how to perform those genres within a real-world context. Yet this model has been critiqued within technical and professional communication, as it can burden the nonprofit staff, whose goal is not to teach undergraduates but rather carry out the mission of their organization (Kimme Hea \& Wendler Shah, 2016). Additionally, this model may not allow for students to experiment with the most rhetorically difficult, and typically highest-stakes, work of the organization, which changes by organization and rhetorical situation. A sanitized experience can provide students a false sense of the kind of work actually being done in nonprofits and affirm students in their belief that genres within nonprofit communication are indeed only transactional. To avoid these obstacles, and to keep the focus on the students' own situatedness, I omitted the service element and instead brought in guest critics to comment on student work. ${ }^{1}$ Guest critics, a common pedagogical feature at our professionally-oriented institution, allowed students to get feedback on how they were navigating genres.

The flexibility of the student relationship with the nonprofit is a distinguishing feature of this assignment, as it allowed students to work with nonprofits that interested them, not only those nonprofits that were interested in serving as a sample organization for students. To organize the class, students were divided into three groups, with each group choosing a local nonprofit to research; the groups contacted their nonprofit to ask for an interview or more information. These organizations represented student interests: one nonprofit provided nutrition-related cooking programs for children, another provided yoga teacher training, and another provided mental health support for youth via social media. The level of interaction with the nonprofits was minimal, if any, and also up to the organization; while both the nutrition and yoga programs responded to initial queries from students, the nutrition program was the only one to follow through on communications throughout the semester, likely because it had the biggest budget and the most staff and therefore the greatest ability to accommodate outside requests. In the absence of individualized data from the organization, student groups used the nonprofit's web presence for textual evidence about the organization.

The reflective genre analysis functions similarly to a portfolio, as students cite their 
own written work to create their arguments about their own rhetorical effectiveness. To complete the genre analysis, students use one of the course's texts on rhetorical genre studies to clarify how their own work did or did not fit genre conventions. For example, one group studying a yoga teacher training organization proposed a series of one-day sample teacher trainings and found a grant from the City of Trenton, NJ, where the organization is located, that could fund the program. They wrote the grant, submitting it to me instead of the city, and then used this application as the artifact for examination in the reflective genre analysis.

The readings for the course prepared students to analyze discourse communities from the perspective of genre. Students read about how genres operate (Bazerman, 2014; Kain, 2014; Russell, 2016), about specific rhetorical practices within technical and professional communication (Small, 2017) and the consequences these strategies have within the nonprofit sector (David, 1999). Using the heuristic offered in Bawarshi and Reiff's (2010) chapter on rhetorical genre studies, we used class time to analyze the conventions of sample genres related to the students' chosen nonprofits. As Bawarshi and Reiff recommend, we collected samples of one genre and looked for patterns in those samples' rhetorical situations, exigencies, patterns of language, and formatting. One genre we examined was the "Get Involved" tab on the nonprofits' webpages, where each nonprofit conformed to genre conventions such as displaying a preferred method of contact and a statement of welcome. The variations among the organizations, however, were clues to the cultural conditions to which the nonprofits respond. Buddy Project, which pairs social media users to safeguard one another's mental health online, offers those who want to "get involved" fillable text boxes for potential volunteers to submit testimonials about their own engagement with mental health, which speaks to their desire to curate the kind of information the public can submit. The "Support Us" tab on the Vetri Community Partnership page, however, offers an option to donate money and prominently lists the organization's Employer Identification Number for easy tax-deductible donations. During discussion, students easily identified the differences in audiences for these two pages and spent more time pondering the cultural roots linked to the organizations' rhetorical choices. After several class discussions, students identified that the rhetorical situation of the Vetri Community Partnership, the nonprofit arm of a successful Philadelphia restaurant chain, was committed to financial involvement, as fine dining invokes a sense of abundance and wealth, whereas Buddy Project was interested in story because one of its main rhetorical appeals was authenticity and being true to oneself. Ultimately, the RGS framework helped these professionally-oriented students to see that communication within nonprofits is flexible and dependent on the rhetorical context.

To further show students how their professional communication is context-driven, I asked students to explicitly link their own personal values to the professional genres in which they wrote. To do so, the class Skyped with a nonprofit executive coach, who prompted us to think about our own "personal codes," or lists of broad professional values, as a reflective activity. The codes were lists of statements intended to remind the students of their emerging professional priorities: for example, "all conflict is not 
injustice," suggesting that conflict in professional settings can be generative. After the Skype session, students wrote their own personal codes in class and shared them with the group. While these codes were not graded, they served as the basis for the students' evaluation of their own rhetorical performances.

In the reflective portions of the assignment, students measured their success in the genre based on how they navigated their own values. For example, student Rachel wrote in her personal code about being a mental health advocate, noting, "everyone's story is equal." In the reflective genre analysis, she examined how this personal priority was not reflected in her navigation of a grant application for a mental health organization:

I believe that the only way to reduce stigma around mental health is to speak about it whenever necessary; by speaking about my personal mental health story, I am reducing the silence and stigma, which is created by the silence of the topic in today's daily conversations. Mental health becomes normalized by transparently talking about the topic. However, in completing the PPA Project Stream Grant application for the Buddy Project, I feel that I did not allow my voice as a mental health advocate [to] come through. [...] I felt that to receive the grant, the Buddy Project would have to remove their genre conventions specific to their community of people, to replace them with the genre conventions of the grant sponsor. I wish I challenged myself to prove this is not the case.

Rachel may mean "values" instead of "genre conventions" in the last two lines, but what I take away from her writing is that she advocates for the destigmatization of mental health through sharing her own story about mental illness, and the genre conventions of the grant application prevented her from doing so. "Speaking about [her] personal mental health story" defines Rachel as a mental health advocate, and her belief that "everyone's story is equal" demonstrates the importance of testimony in her emerging professional identity; yet the conventions of the grant genre prevented her from advocating personally for the destigmatization of mental health. What I hope Rachel and the other students learned from the assignment is not that the genre of the grant application is wrong (although certainly one could argue that), but that nonprofit professionals must be attentive to the constraints of the rhetorical situation and find creative ways or alternative venues to express their personal and professional priorities if the genre does not allow for it. Ultimately, I wanted students to examine how their own values intersected with the genre, and what they could do to (re)define, (re)examine, and/or call into question genre conventions that do not serve their values or the values of a relevant community.

\section{Challenges}

While the assignment was effective overall, there were challenges that arose due to a lack of communication between the students and the nonprofits they were studying and the timing of the assignment within the course. Because this was a portfolio-like assignment 
due electronically during our final exam time after many students had already left campus for the semester, I did not spend as much time drafting and commenting on student work as I normally would have. The prompt is complex, asking students to synthesize their own values and analysis of a genre, and I encouraged them to be creative with the format and not to separate the reflection from the analysis of the genre; you can see that Rachel's argument combines reflection on her own work with genre analysis. However, the many components of the assignment were too much for some students, with the weaker submissions compartmentalizing main points and/or misusing terms from the rhetorical genre studies readings. More drafting and feedback would have helped with these problems.

\section{Conclusion}

Working with the nonprofits of their choice, to whatever extent, allowed students to imagine themselves performing their own values in professional situations. As they prepared to write the reflective genre analysis during the last few days of class, the students were also simultaneously interviewing for internships for the following semester. Our discussions about the intersections of the students' values with the written nonprofit genres prompted organic discussion about how to perform those values in other professional genres, like job interviews.

While many nonprofit writing courses ask students to write a nonprofit genre as a service to a community partner, the lack of service in this assignment, coupled with the examination of students' own values, shifted the focus to students' own rhetorical flexibility. As employers continue to focus on the need for critical thinking and broad learning over field-specific skills (Hart Research Associates, 2015), students, especially those steeped in professionally-oriented learning environments, need practice identifying and performing this flexibility.

\section{Assignment-Reflective Genre Analysis}

See the Supplementary Files for this article at thepromptjournal.com for a PDF facsimile of the original formatting of this assignment.

In her conclusion to A Rhetoric of Reflection, Kathleen Blake Yancey (2016) writes that "reflection is a process we use to make meaning and make knowledge, a kind of meaning and knowledge [...] given its intersectionality, its insistence that only through bringing the human and the world together to theorize can a reflective knowledge and meaning be made" (p. 304).

In this assignment you will conduct a genre analysis of your funding proposal from earlier this semester. Using the genre analysis skills learned in the first part of the semester, 
consider how you navigated and/or negotiated the genre conventions of the funding application. To do this analysis, you will need to identify the genre conventions that are typical of the funding opportunities such as the one for which you applied, and then identify whether or not the funding proposal you created was "typical." Do you think your proposal would be successful for the intended audience, within the given rhetorical situation? Why/ why not?

From here, reflect on how you navigated these genre conventions. You might consider the following:

- How and why did you choose the format for your proposal? What constraints and affordances of the rhetorical situation informed your decision?

- How did your use of genre and/or appeals accommodate or manage these affordances and constraints?

- What were your areas of strength in the proposal? Weaknesses?

- Which rhetorical appeals did you use and how might you have employed them more successfully?

- How do your values as a communications professional intersect (or not) with the genre conventions you used?

- What can you do to (re)define, (re)examine, and/or call into question genre conventions that do not serve your values or the values of a relevant community?

In order to build your argument, you should cite at least two texts: one text from our course reading that helps you frame your understanding of genre, and your own funding proposal. All work should be cited in MLA format.

Other than that, the format of the actual document is up to you-please feel free to be creative! While the length of the essay is up to you, I would imagine you would need about 5-8 double-spaced pages to accomplish these tasks.

This assignment is due before our final exam period. Unlike our other assignments, which have been submitted publicly via the Discussion Board thread on BlackBoard, this assignment will be submitted directly to the Assignments section on BlackBoard in order to maintain your privacy should you want to explore sensitive issues related to group collaboration, etc. 


\section{Grading Rubric: Reflective Genre Analysis}

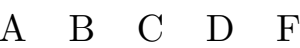

Overall argument

Discussion and application of genre framework to your own work

Depth and precision of reflection

Style (including tone, organization, sentence-level construction)

\section{Notes}

${ }^{1}$ These guest critics were from the Food Moxie and The Colored Girls Museum, both in Philadelphia, PA.

\section{References}

Allen, N., \& Benninghoff, S. T. (2004). TPC program snapshots: Developing curricula and addressing challenges. Technical Communication Quarterly, 13(2), 157-185. http: //doi.org/10.1207/s15427625tcq1302_3

Barrett, K. (2013). Where professional writing meets social change: The grant proposal as a site of hospitality. Composition Studies, 41(1), 70-83.

Bawarshi, A. S., \& Reiff, M. J. (2010). Rhetorical genre studies approaches to teaching writing. Genre: An Introduction to History, Theory, Research, and Pedagogy, 189-209.

Bazerman, C. (2014). Speech acts, genres, and activity systems: How texts organize activity and people. In E. Wardle \& D. Downs (Eds.), Writing About Writing: A College Reader (2nd ed., pp. 365-394). Routledge.

Brady, M. A., \& Schreiber, J. (2013). Static to dynamic: Professional identity as inventory, invention, and performance in classrooms and workplaces. Technical Communication Quarterly, 22(4), 343-362.

David, C. (1999). Elitism in the stories of US art museums: The power of a master narrative. Journal of Business and Technical Communication, 13(3), 318-335.

Foundation Center. (n.d.). How are nonprofits funded? Grantspace: A service of Foundation Center.

Grouling, J. (2018). Training writing teachers: An assignment in mapping writing 
program values. Prompt: A Journal of Academic Writing Assignments, 2(1), 5-16.

Hart Research Associates. (2015). Falling short? College learning and career success. Association of American Colleges and Universities.

Kain, D. (2014). Activity theory: An introduction for the writing classroom. In E. Wardle \& D. Downs (Eds.), Writing about Writing: A college reader (2nd ed., pp. 273-283). New York, NY: Bedford/St. Martin's.

Kimme Hea, A. C., \& Wendler Shah, R. (2016). Silent partners: Developing a critical understanding of community partners in technical communication service-learning pedagogies. Technical Communication Quarterly, 25(1), 48-66.

McKeever, B. S., \& Pettijohn, S. L. (2014). The nonprofit sector in brief 2014: Public charities, giving, and volunteering. The Urban Institute.

NSSE. (2012). National Survey of Student Engagement. Philadelphia University: Mean Comparisons. Unpublished paper.

Russell, L. R. (2016). Defining moments: Genre beginnings, genre invention, and the case of the English language dictionary. In A. Bawarshi \& M. J. Reiff (Eds.), Genres and the performance of publics (pp. 83-99). Logan, UT: Utah State University Press.

Small, N. (2017). (Re) Kindle: On the value of storytelling to technical communication. Journal of Technical Writing and Communication, 47(2), 234-253.

Taczak, K. (2015). Reflection is critical for writers' development. In L. Adler-Kassner \& E. Wardle (Eds.), Naming what we know: Threshold concepts of writing studies (pp. 78-79). Logan, UT: Utah State University Press.

Yancey, K. B. (2016). Defining reflection: The rhetorical nature and qualities of reflection. In K. B. Yancey (Ed.), A rhetoric of reflection (pp. 303-320). Logan, UT: Utah State University Press. 